\title{
Lack of Transient Receptor Potential Vanilloid-1 Enhances Th2-Biased Immune Response of the Airways in Mice Receiving Intranasal, but Not Intraperitoneal, Sensitization
}

\author{
Tetsuya Mori $^{a}$ Katsuyo Saito ${ }^{a}$ Yasushi Ohki ${ }^{b}$ Hirokazu Arakawa ${ }^{b}$ \\ Makoto Tominagac Kenichi Tokuyamad, e \\ a Laboratory of Allergy and Immunology, Faculty of Pharmacy, Takasaki University of Health and Welfare, Takasaki, \\ ${ }^{b}$ Department of Pediatrics and Developmental Medicine, Gunma University Graduate School of Medicine, \\ Maebashi, 'Division of Cell Signaling, Okazaki Institute for Integrative Bioscience, Okazaki, and d Department of \\ Pediatrics and ${ }^{\mathrm{e}}$ Allergy Center, Saitama Medical University, Moroyama, Japan
}

\section{Key Words}

Asthma $\cdot$ Capsaicin $\cdot$ Eosinophil $\cdot$ Neurogenic

inflammation $\cdot$ Vanilloid receptor

\begin{abstract}
Background:Transient receptor potential vanilloid-1 (TRPV1) may modulate allergic airway inflammation because it is expressed not only on the nerve endings but also on several cells of the immune system. We wanted to know the characteristics of airway and systemic responses against sensitization and challenge with allergens in TRPV1 receptor gene knockout mice (TRPV1 ${ }^{-/-}$). Methods: TRPV $1^{-/-}$and their wildtype counterparts $\left(\mathrm{TRPV}^{+/+}\right)$were sensitized with either house dust mite (HDM) or ovalbumin (OVA) via intranasal (i.n.) or intraperitoneal (i.p.) route before the final i.n. challenge with the corresponding allergen. One day after the final challenge, serum IgE levels, cytokine levels in the bronchoalveolar lavage fluid (BALF), and the number of BALF cells were examined after measuring bronchial hyperresponsiveness against methacholine. Results: Compared to TRPV $1^{+/+}$, $\mathrm{TRPV}^{-/-}$showed enhanced Th2-biased response after i.n. HDM or OVA sensitization, including increased levels of serum IgE, interleukin 4 (IL-4) and eosinophils in the BALF. By
\end{abstract}

contrast, when sensitized via i.p. route, the response against OVA or HDM was almost similar between $\mathrm{TRPV} 1^{+/+}$and $\mathrm{TRPV}^{-/-}$. Conclusion: TRPV1 receptor may downregulate Th2-biased immune response when sensitized via airways, although this was not the case when sensitized systemically.

Copyright $\odot 2011$ S. Karger AG, Basel

\section{Introduction}

Transient receptor potential vanilloid-1 (TRPV1) is a member of a family of TRPV receptors, which mediates stimuli of the sensory neuron and percepts heat by the nervous system. TRPV1 is known to be specifically activated not only by high temperatures $\left(43^{\circ} \mathrm{C}\right)$ but also by various stimuli such as capsaicin. In addition to certain sensory neurons, TRPV1 has recently been reported to be expressed (albeit at much lower levels compared with sensory neurons) in various nonneuronal cells, such as keratinocytes [1], smooth muscle cells [2], endothelial cells [3] and cells of the immune system, including mast cells, lymphocytes and dendritic cells (DCs) [4-7].

In the airways, TRPV1 has been proposed to play a role in several features of respiratory diseases, including

\section{KARGER}

Fax +4161306 1234 E-Mail karger@karger.ch www.karger.com

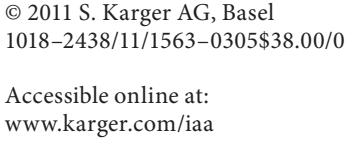


chronic cough [8], chronic obstructive pulmonary disease and asthma [9]. In asthma, TRPV1 has been suggested to have a key role in the pathophysiology by causing neurogenic airway inflammation. In this hypothesis, TRPV1 located on the sensory C-fiber nerve endings is denuded onto the surface of injured and desquamated airway epithelium, one of the characteristic features of asthma pathology. As a result, TRPV1 is easily activated by many stimuli and releases neuropeptides such as substance $\mathrm{P}$, neurokinin A and calcitonin gene-related peptide from its nerve endings, possibly via retrograde conduction (axon reflex). These peptides are demonstrated to have airway effects which mimic the pathophysiology of asthma, including mucus hypersecretion, increased microvascular permeability and smooth muscle contraction [10].

TRPV1 may also contribute to the development of airway inflammation seen in asthma. Several evidences have been demonstrated to support this hypothesis. First, interactions between neuropeptides such as tachykinins and inflammatory cells such as macrophages and mast cells are reported [11]. These cells are known to modulate immune responses. Second, heat, one of the major causative stimuli of TRPV1 receptor, has an equally profound effect on the immune system [12-15], although its perception by the immune system is poorly understood. Third, as mentioned above, TRPV1 is shown to be expressed on cells of the immune system, including mast cells, lymphocytes and DCs [4-7], all of which are important in the development of adoptive immunity.

Thus, in the present study, we wanted to know the role of TRPV1 in the development of allergic airway sensitization. For this purpose, we examined the characteristics of the response in TRPV1 receptor gene knockout mice $\left(\mathrm{TRPV}^{-/-}\right)$after sensitization and challenge with allergens. TRPV1 $1^{-/}$and wild-type C57BL/6 mice $\left(\mathrm{TRPV}^{+/+}\right.$) were sensitized with two different allergens via different routes: intranasal (i.n.) and intraperitoneal (i.p.). Then, the animals were intranasally challenged with the corresponding allergen. As the allergens, we used ovalbumin (OVA) and house dust mite (HDM), major food and inhalant allergens in allergic individuals, respectively.

\section{Animals and Methods}

Animals

Wild-type mice (C57BL/6) purchased from Japan SLC (Shizuoka, Japan) and TRPV1-deficient mice [16] backcrossed on a C57BL/6 background were used. The TRPV1 ${ }^{-/-}$mice were provided by Dr. D. Julius [16] and were reared in the animal care fa- cilities of Takasaki University of Health and Welfare. All experiments were performed using 7- to 9-week-old male animals. All mice were bred under specific pathogen-free conditions at 24$25^{\circ} \mathrm{C}$ and a 12-hour/12-hour light/dark cycle provided with standard chow and water ad libitum. All procedures were conducted in accordance with the policy of the Animal Care and Use Committee at the Takasaki University of Health and Welfare.

Sensitization and Airway Challenge Protocol

Eight experimental groups with corresponding nonsensitized controls were developed (7-11 and 5-8 mice for each sensitized and nonsensitized group, respectively).

$\mathrm{TRPV}^{-/-}$and their wild-type counterparts $\left(\mathrm{TRPV}^{+/+}\right)$were sensitized with either HDM (Mite extract-Df; Cosmo Bio, Tokyo, Japan) or OVA (grade V; Sigma-Aldrich, St. Louis, Mo., USA) via i.n. or i.p. route before the final i.n. challenge with the corresponding antigen. The nonsensitized animal in each group was given same volume of vehicle instead of each allergen. The allergen exposure protocols were as follows: animals given i.n. HDM sensitization: HDM was given by modifying the protocol by Shibamori et al. [17]. Mice were anesthetized with an i.p. injection of $50 \mathrm{mg} / \mathrm{kg}$ of sodium pentobarbital, followed by i.n. instillation of $100 \mu \mathrm{g}$ of HDM in $50 \mu \mathrm{l}$ of PBS or the same volume of PBS. The same dose of allergen or PBS alone was given intranasally on 5 consecutive days (days $0-4$ ) and days 14 as well as 15 , and challenged on days 21 and 22 .

Animals given i.p. HDM sensitization: mice were immunized intraperitoneally with $10 \mu \mathrm{g}$ of $\mathrm{HDM}$ in $1 \mathrm{mg}$ of alum $\left(\mathrm{AlOH}_{3}\right)$ or $1 \mathrm{mg}$ of alum alone on day 0 and boosted on days 7 and 14. Subsequently, mice were anesthetized with sodium pentobarbital and $100 \mu \mathrm{g}$ of HDM in $50 \mu \mathrm{l}$ PBS or PBS alone, and were challenged via i.n. instillation on days 21 and 22 .

Animals given i.n. OVA sensitization: using $100 \mu \mathrm{g}$ of OVA instead of HDM, allergen sensitization and challenge were carried out with the same schedule as the protocol of i.n. HDM sensitization.

Animals given i.p. OVA sensitization: mice were immunized intraperitoneally with $10 \mu \mathrm{g}$ of OVA in $1 \mathrm{mg}$ of $\mathrm{AlOH}_{3}$ or alum alone on day 0 and boosted on days 7 and 14 as described previously [18]. After anesthesia, $2 \mathrm{mg}$ of i.n. OVA in $50 \mu \mathrm{l}$ PBS or PBS alone were given twice on day 21 and once on days 22 and 23 .

\section{Determination of Bronchial Hyperresponsiveness}

Twenty-four hours after the last allergen challenge, mice were anesthetized with $50 \mathrm{mg} / \mathrm{kg}$ pentobarbital and instrumented for the measurement of pulmonary mechanics (BUXCO Electronics, Suita, Japan). Mice were tracheostomized, intubated and mechanically ventilated at a tidal volume of $0.2 \mathrm{ml}$ and a frequency of 150 breaths/min. Mice were paralyzed with suxamethonium chloride $\left(5 \mathrm{mg} / \mathrm{kg}\right.$ i.p.). Baseline lung resistance $\left(\mathrm{R}_{\mathrm{L}}\right)$ and responses to aerosolized saline $(0.9 \% \mathrm{NaCl})$ were measured first, followed by responses to increasing doses $(0.19$ to $500 \mathrm{mg} / \mathrm{ml})$ of aerosolized acetyl-methylcholine chloride (methacholine, Mch; SigmaAldrich). The highest values of $\mathrm{R}_{\mathrm{L}}$ were obtained after each dose of Mch. Bronchial hyperresponsiveness (BHR) was evaluated utilizing 3 parameters: (1) Mch concentration required for $100 \% \mathrm{R}_{\mathrm{L}}$ increase from the baseline value referred to as $\mathrm{PC}_{200}$, (2) the leftward shift of the dose-response curve, (3) the absolute value of $\mathrm{R}_{\mathrm{L}}$ corresponding to the maximum Mch concentration $(500 \mathrm{mg} / \mathrm{ml})$ referred to as maximum reactivity (MaxR). 


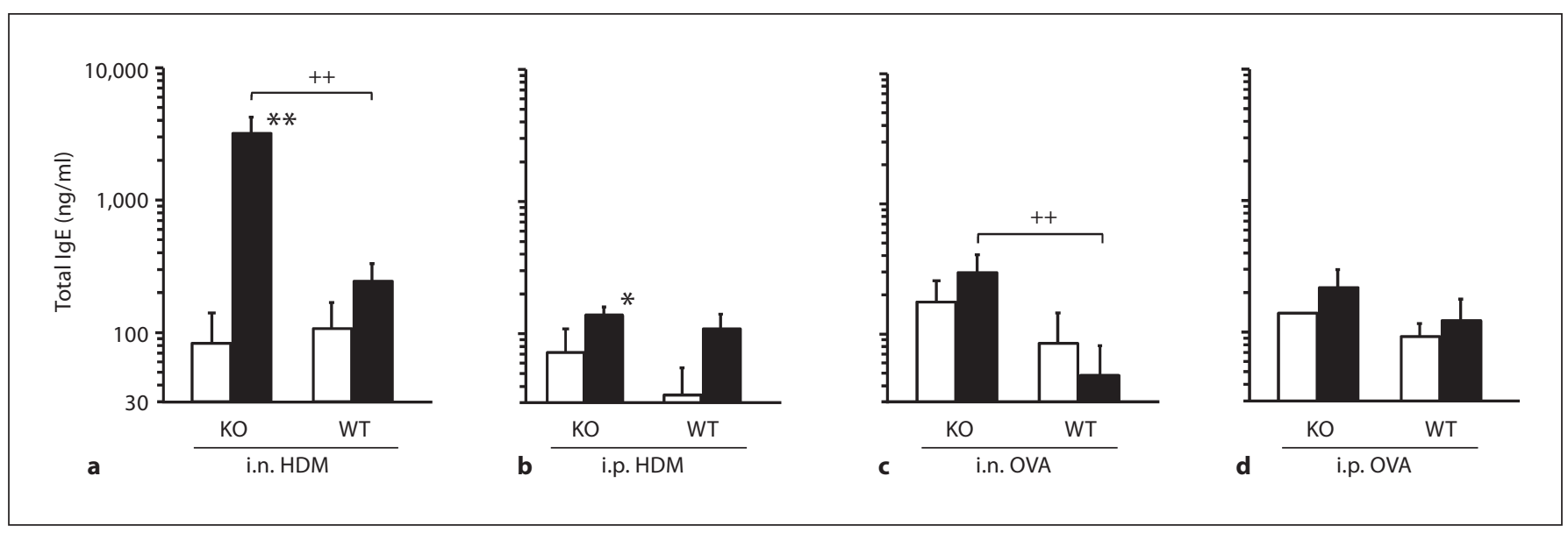

Fig. 1. Total IgE levels in the serum. Total IgE levels in animals given sensitization with i.n. HDM (a), i.p. HDM (b), i.n. OVA (c) or i.p. OVA (d) are shown. The open and closed columns indicate the values of animals with and without sensitization and challenge of allergen, respectively. KO and WT indicate TRPV1 recep- tor gene knockout (TRPV1 ${ }^{-/-}$) and wild-type mice $\left(\mathrm{TRPV}^{+/+}\right)$, respectively. Values are expressed as means \pm SEM. ${ }^{*} \mathrm{p}<0.05$ and ${ }^{* *} \mathrm{p}<0.01$ vs. corresponding animals without sensitization and challenge; ${ }^{++} \mathrm{p}<0.01$ between TRPV1 ${ }^{-/-}$and TRPV $1^{+/+}$.

\section{The Sampling Procedure of Blood and Bronchoalveolar}

\section{Lavage Fluid}

After assessment of BHR, mice were sacrificed and blood was collected by cardiac puncture to obtain serum samples. After getting the samples, lungs were lavaged with $0.4 \mathrm{ml}$ of phosphate-buffered saline ( $\mathrm{pH}$ 7.4) 3 times. The bronchoalveolar lavage fluids (BALF) were centrifuged at 3,000 rpm for $5 \mathrm{~min}$. The supernatant was preserved for the measurement of cytokine levels at $-70^{\circ} \mathrm{C}$. The cell pellet was resuspended in $0.3 \mathrm{ml}$ of phosphate-buffered saline. The total cell counts were performed with a hemocytometer, and the differential cell counts were performed on cytospin preparations stained with Diff-Quick (Kokusai-Siyaku, Tokyo, Japan). A blinded observer counted a minimum of 200 cells for each sample.

Determination of Total IgE Antibodies

Total IgE levels were measured by using commercially available ELISA kits (Shibayagi, Shibukawa, Japan).

\section{Measurement of BALF Cytokines}

IL-4, IFN- $\gamma$, IL-5 and eotaxin levels were measured by commercially available ELISA kits (for IL- 4 and IFN- $\gamma$ : Endogen, Boston, Mass., USA; for IL-5 and eotaxin: R\&D Systems, Minneapolis, Minn., USA). The detection limit was $15 \mathrm{pg} / \mathrm{ml}$ for all these cytokines.

\section{Statistical Analysis}

All data are expressed as means \pm SEM, unless mentioned otherwise. Nonparametric analysis of variance (Kruskal-Wallis test for unmatched pairs) was used to determine the significance of variance between groups. If a significance of variance was found, a Mann-Whitney U test was performed to assess the significance of differences between groups. A p value of less than 0.05 was considered to indicate statistical significance. The statistical analysis was performed utilizing Statview version 4.5 (Avacus Concepts Inc., Berkeley, Calif., USA).

\section{Results}

\section{Total IgE Levels}

In all groups of $\mathrm{TRPV}^{+/+}$given sensitization and challenge with allergen, total IgE level did not differ from corresponding animals without sensitization. In TRPV1 ${ }^{-1}$, a significant increase in total IgE level was found in animals sensitized and challenged with HDM compared to nonsensitized animals, irrespective of the route of sensitization. In TRPV1 ${ }^{-/-}$given i.n. sensitization with HDM, total IgE level was significantly higher than that in corresponding $\mathrm{TRPV1}^{+/+}$, although this was not the case in those given i.p. sensitization (fig. 1a, b). In TRPV1 ${ }^{-/}$given i.n. sensitization with OVA, IgE level was significantly higher than that in corresponding $\mathrm{TRPVI}^{+/+}$, although no difference was found between TRPV1 ${ }^{-1-}$ with and without i.n. OVA sensitization. In TRPV1 ${ }^{-/-}$given i.p. sensitization, no increase in IgE levels was found (fig. 1c, d).

\section{BALF Cytokine Levels}

In TRPV ${ }^{+/+}$, significant increase in BALF IL-4 was observed in those given sensitization with HDM, irrespective of the route. By contrast, no significant increase was found in those sensitized with OVA. In TRPV1 ${ }^{-1}$, i.n. but not i.p. sensitization with HDM induced significantly greater increase in IL-4 compared to TRPV1 ${ }^{+/+}$; i.n. but not i.p. sensitization with OVA induced significant increase in IL-4 compared to those without sensitization (fig. 2). 


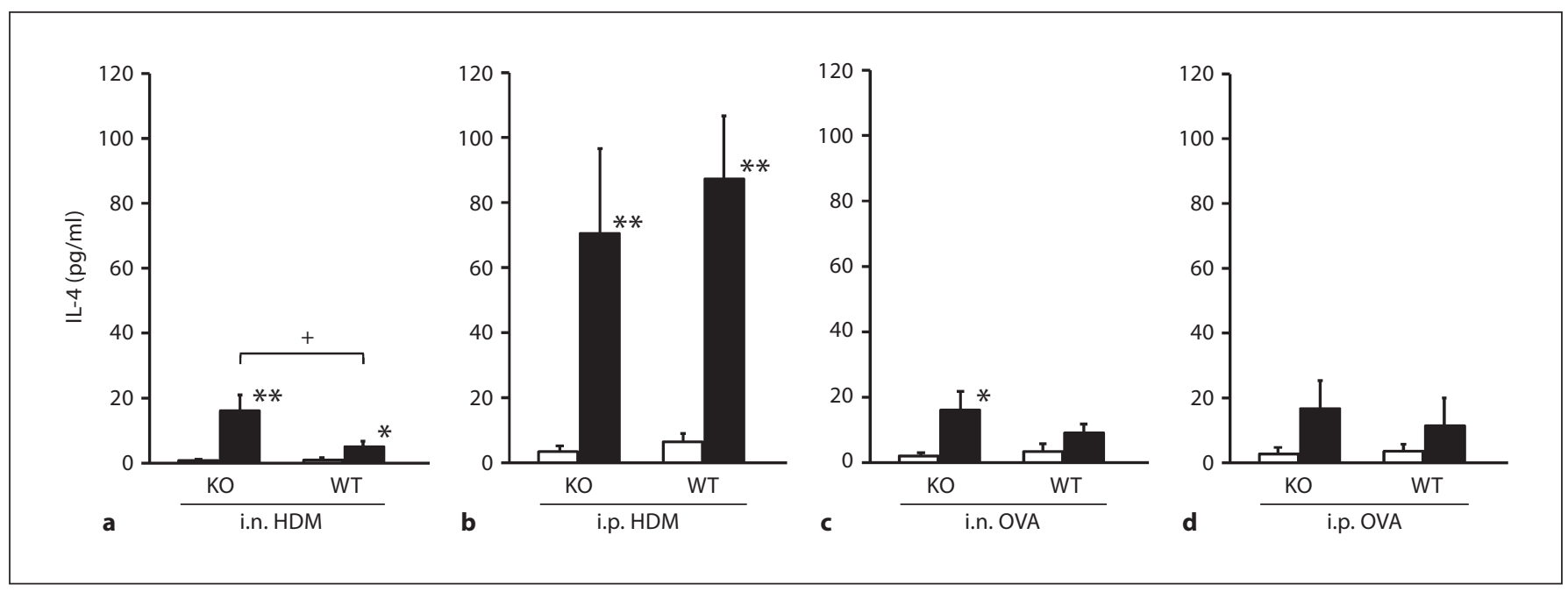

Fig. 2. IL-4 levels in the BALF. IL-4 levels in animals given sensitization with i.n. HDM (a), i.p. HDM (b), i.n. OVA (c) or i.p. OVA (d) are shown. The open and closed columns indicate the values of animals with and without sensitization and challenge of allergen, respectively. $\mathrm{KO}$ and $\mathrm{WT}$ indicate TRPV1 receptor gene knockout
$\left(\mathrm{TRPV}^{-/-}\right)$and wild-type mice $\left(\mathrm{TRPV} 1^{+/+}\right)$, respectively. Values are expressed as means \pm SEM. ${ }^{*} p<0.05$ and ${ }^{* *} p<0.01$ vs. corresponding animals without sensitization and challenge; ${ }^{+} \mathrm{p}<0.05$ between TRPV1 ${ }^{-/-}$and TRPV1 ${ }^{+/+}$.

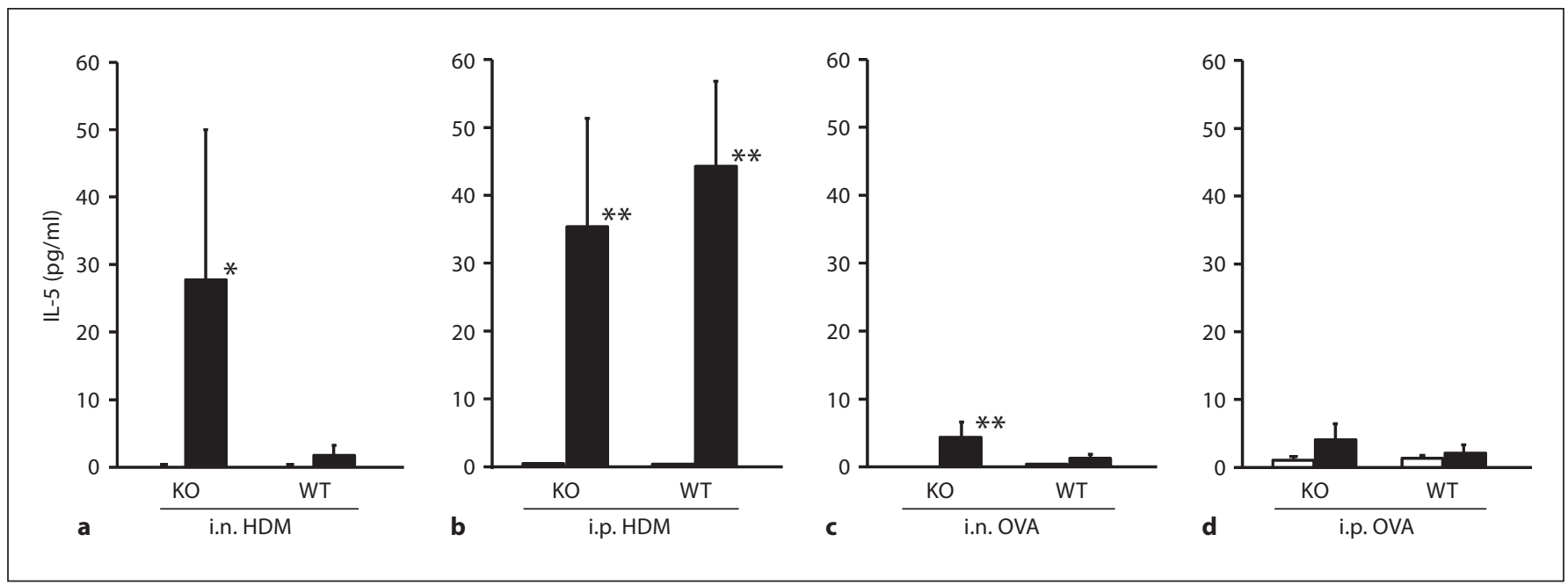

Fig. 3. IL-5 levels in the BALF. IL-5 levels in animals given sensitization with i.n. HDM (a), i.p. HDM (b), i.n. OVA (c) or i.p. OVA (d) are shown. The open and closed columns indicate the values of animals with and without sensitization and challenge of allergen, respectively. $\mathrm{KO}$ and $\mathrm{WT}$ indicate TRPV1 receptor gene knockout $\left(\mathrm{TRPV}^{-/-}\right.$) and wild-type mice (TRPV1 ${ }^{+/+}$), respectively. Values are expressed as mean \pm SEM. ${ }^{*} \mathrm{p}<0.05$ and ${ }^{* *} \mathrm{p}<0.01$ vs. corresponding animals without sensitization and challenge.
IL-5 significantly increased in animals given sensitization with HDM, irrespective of the route in TRPV $1^{+/+}$, although this was not the case for those given sensitization with OVA (fig. 3). In TRPV1 ${ }^{-1-}$, i.n. but not i.p. OVA sensitization induced significant increase in IL-
5; i.n. HDM sensitization caused elevated IL-5 levels in TRPV1 ${ }^{-/-}$compared to TRPV1 ${ }^{+/+}$, although this was not significant. In animals given i.p. HDM, similar degree of increase in IL-5 was found in TRPV1 ${ }^{+/+}$and TRPV1 $1^{-/-}$ (fig. 3). 
Fig. 4. Representative photomicrographs of BALF cells in animals given i.n. HDM sensitization and challenge (Diff-Quick staining). The percentage of eosinophils was higher in TRPV1 receptor gene knockout mice (a) than in wild-type animals (b). Scale bars $=10 \mu \mathrm{m}$. The eosinophils are indicated by red staining.

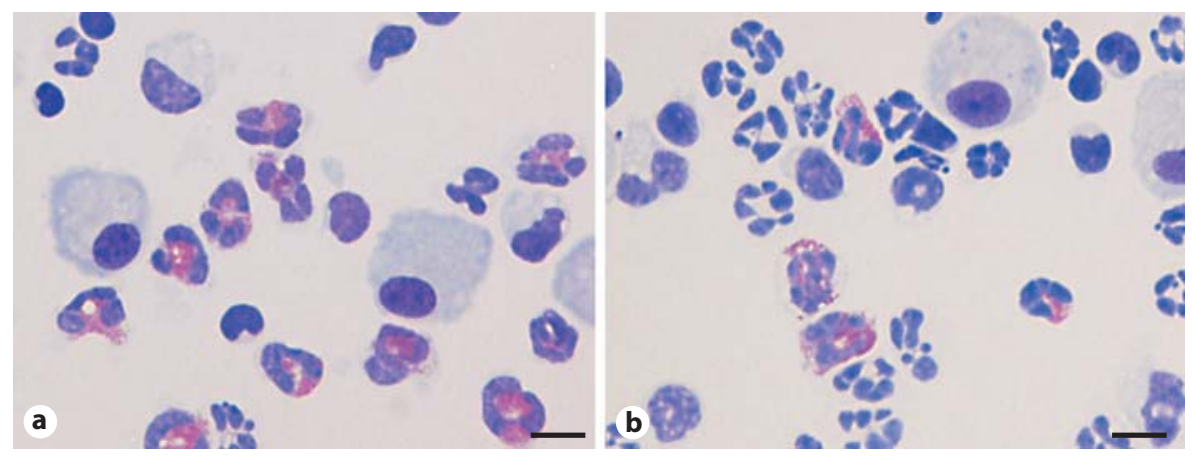

i.p. sensitization with either HDM or OVA caused a significant elevation of the eotaxin level compared to corresponding nonsensitized animals in both TRPV1 $1^{+/+}$ and TRPV1 ${ }^{-/-}$. The degree was similar between 2 groups of animals. i.n. sensitization caused a significant elevation of the eotaxin level compared to corresponding nonsensitized animals only in TRPV $1^{-/-}$sensitized with HDM.

i.n. sensitization with HDM induced a significant decrease in IFN- $\gamma$ level compared to corresponding nonsensitized animals in both $\mathrm{TRPV} 1^{+/+}$and $\mathrm{TRPV} 1^{-/-}$. The degree was similar between 2 groups of animals. i.n. sensitization with OVA caused a significant decrease in this cytokine compared to corresponding nonsensitized animals in $\mathrm{TRPV}^{+/+}$but not TRPV1 ${ }^{-/-}$. i.p. sensitization did induce significant decrease in neither of the groups.

\section{Cells in the BALF}

Total cells in the BALF increased in all groups of animals given sensitization and challenge compared to corresponding animals given vehicle. In animals given sensitization with i.n. OVA, the number of total cells in $\mathrm{TRPV}^{-/-}$was significantly higher than that in TRPV ${ }^{+/+}$. In detail, the numbers of eosinophils, neutrophils, macrophages and lymphocytes were significantly increased (fig. 5a-d). The percentage of each cell type was not different between $\mathrm{TRPV}^{-/-}$and $\mathrm{TRPV} 1^{+/+}$. In animals given sensitization with i.n. HDM, the number of total cells was not different between TRPV1 $1^{-/}$and TRPV1 ${ }^{+/+}$. However, the percentage of eosinophils was significantly higher in $\mathrm{TRPV1}^{-/-}$than TRPV1 ${ }^{+/+}$(fig. 4, 5e-h). There was no difference in the percentage of other cell types, including neutrophils, macrophages and lymphocytes. In animals given i.p. administration of allergen, there was no difference in the number and the percentage of differential cell counts between TRPV1 ${ }^{-/-}$and TRPV $1^{+/+}$.

\section{Bronchial Responsiveness to Mch}

In all groups of animals studied, allergen sensitization and challenge did not induce BHR to Mch irrespective of $\mathrm{TRPV}^{+/+}$or TRPV1 ${ }^{-/-}$, when comparing $\mathrm{PC}_{200}$, leftward shift of the dose-response curve and MaxR as parameters (data not shown).

\section{Discussion}

We have examined the remarks of allergic airway and systemic responses in TRPV1 receptor gene knockout mice. As a result, TRPV1 ${ }^{-/}$showed an enhanced Th2biased response against i.n. HDM or OVA exposure, including increased levels of serum IgE, and IL-4 and eosinophils in the BALF. By contrast, when sensitized via i.p. route, the difference was not obvious between $\mathrm{TRPV1}^{+/+}$and $\mathrm{TRPV1}^{-/-}$. These results suggest that TRPV1 receptor may downregulate Th2-biased immune response when sensitized via airways, although this was not the case when sensitized systemically.

In the present study, we used $\mathrm{C} 57 \mathrm{BL} / 6$ strain as $\mathrm{TRPV}^{+/+}$and TRPV1 ${ }^{-/-}$. We chose the strain because the knockout mice we had been provided were limited only to that one. In TRPV1 ${ }^{+/+}$, sensitization and challenge with allergens did not induce remarkable Th2-biased immune response, that is, total IgE in the serum did not elevate in any of the groups with sensitization, and IL-4 as well as IL-5 levels were not significantly increased in OVA-treated animals irrespective of the route of sensitization, although eosinophil counts in the BALF increased in all groups given sensitization with allergens. These results confirmed previous observations that the C57BL/6 strain was one of those with less responsiveness to allergen exposure $[17,19,20]$. Shinagawa et al. [20] showed that, in repeated OVA instillation into the nose, eosinophilic inflammation, airway wall thickening and BHR were not 


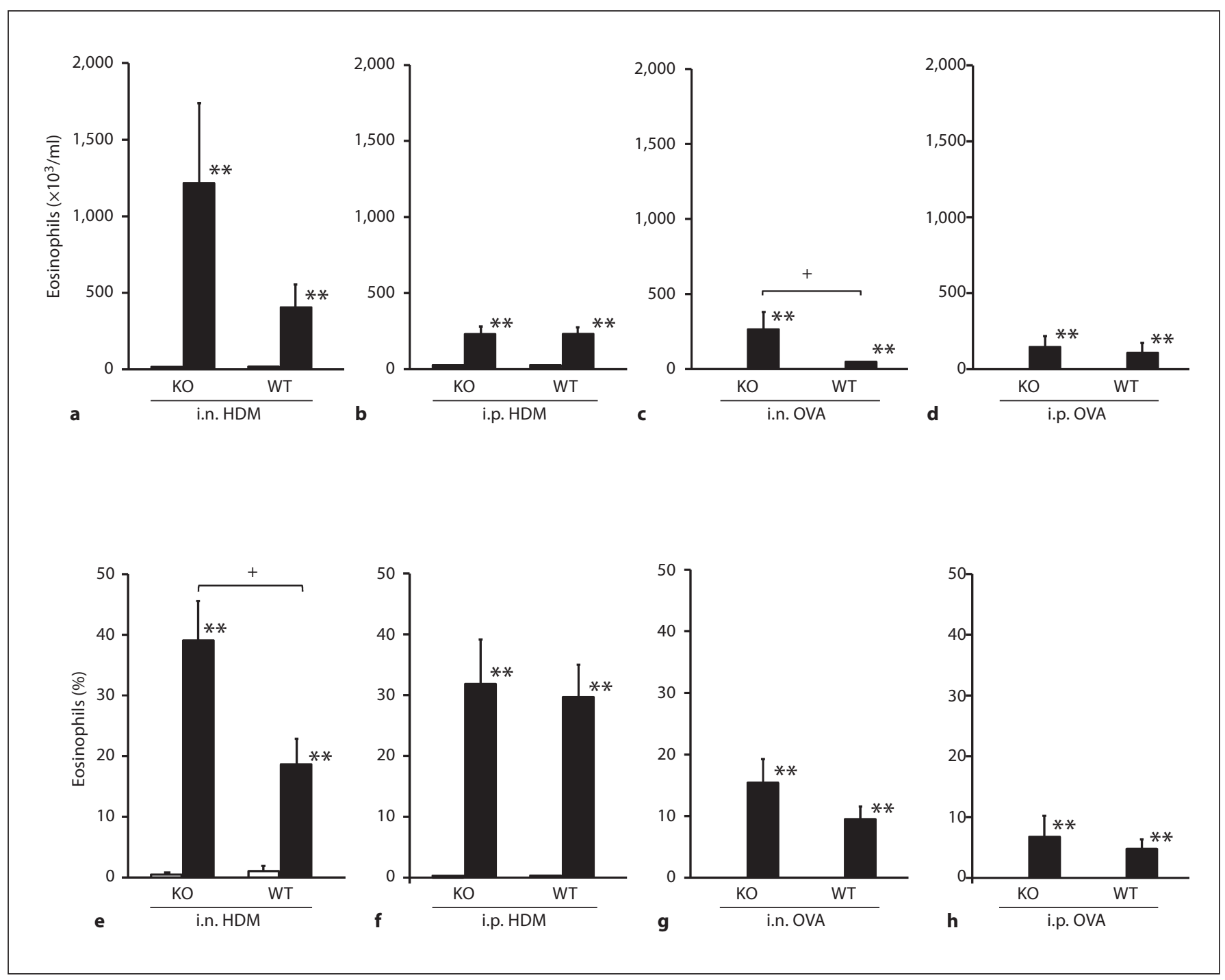

Fig. 5. Eosinophils in the BALF. The total number (a-d) and the percentage of eosinophils in the BALF (e-h) in animals given sensitization with i.n. $\operatorname{HDM}(\mathbf{a}, \mathbf{e})$, i.p. $\operatorname{HDM}(\mathbf{b}, \mathbf{f})$, i.n. OVA $(\mathbf{c}, \mathbf{g})$ or i.p. OVA $(\mathbf{d}, \mathbf{h})$ are shown. The open and closed columns indicate the values of animals with and without sensitization and chal- lenge of allergen, respectively. $\mathrm{KO}$ and $\mathrm{WT}$ indicate TRPV1 receptor gene knockout (TRPV1 ${ }^{-/-}$) and wild-type mice (TRPV1 ${ }^{+/+}$), respectively. Values are expressed as means \pm SEM. ${ }^{*} \mathrm{p}<0.05$ and ${ }^{* *} \mathrm{p}<0.01$ vs. corresponding animals without sensitization and challenge; ${ }^{+} \mathrm{p}<0.05$ between $\mathrm{TRPV} 1^{-/-}$and $\mathrm{TRPV} 1^{+/+}$. observed in $\mathrm{C} 57 \mathrm{BL} / 6$ and $\mathrm{C} 3 \mathrm{H} / \mathrm{HeJ}$ mice, whereas obvious responses were found in $\mathrm{A} / \mathrm{J}$ and $\mathrm{BALB} / \mathrm{c}$ mice. As for i.n. HDM exposure, Shibamori et al. [17] demonstrated that $\mathrm{NC} / \mathrm{Nga}$ mice showed the strongest response, including the number of eosinophils in the BALF, BHR, Th2 cytokine (IL-5 and IL-13) and chemokine (eotaxin-1 and eotaxin-2) levels in the BALF, compared to $\mathrm{C} 57 \mathrm{BL} / 6 \mathrm{~N}$, $\mathrm{A} / \mathrm{J}, \mathrm{BALB} / \mathrm{c}$ and $\mathrm{CBA} / \mathrm{JN}$ strains.

It was interesting that local Th2 cytokines and the number of eosinophils, in addition to serum IgE levels, increased in $\mathrm{TRPV}^{-/-}$compared to $\mathrm{TRPV} 1^{+/+}$. These results suggest that TRPV1 receptor attenuates Th2-biased immune response, indicating that this receptor has an inhibitory effect against the development of allergic airway inflammation. Several possibilities may arise, although we could not clarify the underlying mechanism. First, it is possible that TRPV1 receptors located in nerve endings downregulate Th2-biased responses by releasing sensory neuropeptides such as substance $P$, neurokinin A, calcitonin gene-related peptide and, possibly, soma- 
tostatin [21]. Topically applied allergens have been shown to react with the sensitized local mast cells and then these cells release several inflammatory mediators such as histamine and leukotrienes [22]. These mediators are known to activate TRPV1 which has been demonstrated to control the release of sensory neuropeptides [23]. Evidence has shown that the lack of TRPV1 decreases these peptides [24], although we did not examine the expression patterns of sensory neuropeptides in $\mathrm{TRPV}^{-/-}$of the present study. It is recognized that the immune and nervous systems are closely integrated to optimize defense systems within the lung. When released, these neuropeptides are speculated to have effects on the activation of immune cells including $\mathrm{T}$ cells and professional antigenpresenting DCs [25]. Second, TRPV1 receptors expressed on immune cells may play a role. Recently, TRPV1 has been shown to be expressed not only on sensory nerve endings but also on cells of the immune system, including mast cells, lymphocytes and DCs [4-7], all of which have important roles in the development of adoptive immunity. Among these cells, conflicting findings are reported for the role of TRPV1 receptors in the function of DCs, a key cell type of the vertebrate immune system. Basu and Srivastava [26] demonstrated an expression of TRPV1 on DCs. They reported that engagement of TRPV1 on immature DCs such as by treatment with capsaicin leads to maturation of DCs as measured by upregulation of antigen-presenting and costimulatory molecules. Conversely, Toth et al. [27] demonstrated that capsaicin dose-dependently inhibited cytokine-induced DC differentiation, phagocytosis of bacteria, activation of DCs and proinflammatory cytokine secretion, indicating that TRPV1 receptors have an anti-inflammatory action on DCs. Our present findings may support the functional role of TRPV1 suggested by Toth et al. [27]. Further studies would be required concerning the mechanism of the results obtained in the present study.

Our present results showed that i.n., but not i.p., sensitization induced significant increases in the Th2 response in TRPV1 $1^{-/}$. Our findings partly confirmed previous observations by Caceres et al. [28] demonstrating that airway and systemic responses caused by i.p. OVA sensitization did not differ between TRPV1 $1^{+/+}$ and TRPV1 ${ }^{-/-}$. Although they did not examine the effect of local application of allergens on airway response, they showed that genetic ablation of TRPA1, but not TRPV1 ${ }^{-/-}$, inhibited i.p. OVA-induced leukocyte infiltration in the airways, reduced cy tokine and mucus production, and almost completely abolished airway hyperresponsiveness to contractile stimuli. Our present results suggested that the route of sensitization would be an important factor to evaluate airway effects. It was suggested that the airway sensitization via mucosal allergen entry might be required to activate TRPV1 receptors. In intraperitoneally sensitized animals, only $30 \mu \mathrm{g}$ of allergen in total was applied to peritoneum, reaching the airways mainly via blood flow. By contrast, $500 \mu \mathrm{g}$ of allergen in total was directly applied to the airway mucosa in animals sensitized intranasally.

In the present study, BHR was not induced in all groups of animals given sensitization compared to those given vehicle, irrespective of the route of sensitization. Conflicting results have been reported as for the BHR after OVA exposure in C57BL/6 mice. When given i.p. sensitization, several investigators found that there was no difference in BHR between animals with and without sensitization [19, 29-31], while others indicated an increased bronchial responsiveness in animals given OVA compared to vehicle $[28,32,33]$. As for animals sensitized with i.n. OVA, no difference in the bronchial responsiveness between those with and without allergen exposure was demonstrated by several investigators $[17,20]$. As for i.n. HDM exposure, Shibamori et al. [17] demonstrated that i.n. HDM exposure induced a weak but significant increase in bronchial responsiveness to Mch in C57BL/6N mice. We do not know the reason for the difference between their results and ours. The difference in the details of sensitization and challenge protocol or that in Mch provocation procedures might be the reasons. They gave Mch via intravenous route, while we did it by aerosol. They estimated BHR by the percentage of the respiratory overflow volume provoked by acetylcholine to the maximal overflow volume (100\%) obtained by totally occluding the tracheal cannula, while we did it by measuring lung resistance.

Our results suggest that TRPV1 receptor has a protective role against Th2-biased immune response and, consequently, the development of allergic inflammation in the airways. This may shed light on the pharmacotherapy of allergic airway diseases such as asthma by using agonists of TRPV1 receptors, although further studies would be required. 


\section{References}

-1 Stander S, Moormann C, Schumacher M, Buddenkotte J, Artuc M, Shpacovitch V, et al: Expression of vanilloid receptor subtype 1 in cutaneous sensory nerve fibers, mast cells, and epithelial cells of appendage structures. Exp Dermatol 2004;13:129-139.

$\checkmark 2$ Kark T, Bagi Z, Lizanecz E, Pasztor ET, Erdei N, Czikora A, et al: Tissue-specific regulation of microvascular diameter: opposite functional roles of neuronal and smooth muscle located vanilloid receptor-1. Mol Pharmacol 2008;73:1405-1412.

3 Golech SA, McCarron RM, Chen Y, Bembry J, Lenz F, Mechoulam R, et al: Human brain endothelium: coexpression and function of vanilloid and endocannabinoid receptors. Brain Res Mol Brain Res 2004;132:87-92.

$\checkmark 4$ Wang JP, Tseng CS, Sun SP, Chen YS, Tsai CR, Hsu MF: Capsaicin stimulates the nonstore-operated $\mathrm{Ca}^{2+}$ entry but inhibits the store-operated $\mathrm{Ca}^{2+}$ entry in neutrophils. Toxicol Appl Pharmacol 2005;209:134-144.

$\checkmark 5$ Chen CW, Lee ST, Wu WT, Fu WM, Ho FM, Lin WW: Signal transduction for inhibition of inducible nitric oxide synthase and cyclooxygenase- 2 induction by capsaicin and related analogs in macrophages. Br J Pharmacol 2003;140:1077-1087.

-6 Biro T, Maurer M, Modarres S, Lewin NE, Brodie C, Acs G, et al: Characterization of functional vanilloid receptors expressed by mast cells. Blood 1998;91:1332-1340.

7 Cortright DN, Szallasi A: Neurogenic Inflammation in Health and Disease. Neuroimmune Biol. Amsterdam, Elsevier, 2008, vol 8.

$\checkmark 8$ Groneberg DA, Niimi A, Dinh QT, Cosio B, Hew M, Fischer A, Chung KF: Increased expression of transient receptor potential vanilloid-1 in airway nerves of chronic cough. Am J Respir Crit Care Med 2004;170: 1276-1280.

$\checkmark 9$ Barnes PJ: Asthma as an axon reflex. Lancet 1986;1:242-245.

$>10$ De Swert KO, Joos GF: Extending the understanding of sensory neuropeptides. Eur J Pharmacol 2006;533:171-181.

-11 Joos GF, Germonpre PR, Pauwels RA: Role of tachykinins in asthma. Allergy 2000;55:321337.
12 Nahas GG, Tannieres ML, Lennon JF: Direct measurement of leukocyte motility: effects of $\mathrm{pH}$ and temperature. Proc Soc Exp Biol Med 1971;138:350-352.

13 Bryant RE, Hood AF, Hood CE, Koenig MG: Factors affecting mortality of gram-negative rod bacteremia. Arch Intern Med 1971;127: 120-128.

14 Mullbacher A: Hyperthermia and the generation and activity of murine influenza-immune cytotoxic T cells in vitro. J Virol 1984; 52:928-931.

15 Smith JB, Knowlton RP, Agarwal SS: Human lymphocyte responses are enhanced by culture at $40^{\circ} \mathrm{C}$. J Immunol 1978;121:691-694.

16 Caterina MJ, Leffler A, Malmberg AB, Martin WJ, Trafton J, Petersen-Zeitz KR, et al: Impaired nociception and pain sensation in mice lacking the capsaicin receptor. Science 2000;288:306-313.

17 Shibamori M, Ogino K, Kambayashi Y, Ishiyama $\mathrm{H}$ : Intranasal mite allergen induces allergic asthma-like responses in $\mathrm{NC} / \mathrm{Nga}$ mice. Life Sci 2006;78:987-994.

18 Ohki Y, Tokuyama K, Mayuzumi H, Sato A, Koyama H, Takizawa T, et al: Characteristic features of allergic airway inflammation in a murine model of infantile asthma. Int Arch Allergy Immunol 2005;138:51-58.

19 Ewart SL, Kuperman D, Schadt E, Tankersley C, Grupe A, Shubitowski DM, et al: Quantitative trait loci controlling allergen-induced airway hyperresponsiveness in inbred mice. Am J Respir Cell Mol Biol 2000;23:537-545.

20 Shinagawa K, Kojima M: Mouse model of airway remodeling: strain differences. Am J Respir Crit Care Med 2003;168:959-967.

21 Groneberg DA, Quarcoo D, Frossard N, Fischer A: Neurogenic mechanisms in bronchial inflammatory diseases. Allergy 2004; 59:1139-1152.

-22 Miyahara N, Ohnishi H, Miyahara S, Takeda K, Matsubara S, Matsuda H, et al: Leukotriene $\mathrm{B} 4$ release from mast cells in IgE-mediated airway hyperresponsiveness and inflammation. Am J Respir Cell Mol Biol 2009 . 40:672-682.

23 Bessac BF, Jordt SE: Breathtaking TRP channels: TRPA1 and TRPV1 in airway chemosensation and reflex control. Physiology (Bethesda) 2008;23:360-370.
24 Kichko TI, Reeh PW: TRPV1 controls acidand heat-induced calcitonin gene-related peptide release and sensitization by bradykinin in the isolated mouse trachea. Eur J Neurosci 2009;29:1896-1904.

25 Lambrecht BN: Immunologists getting nervous: neuropeptides, dendritic cells and $\mathrm{T}$ cell activation. Respir Res 2001;2:133-138.

26 Basu S, Srivastava P: Immunological role of neuronal receptor vanilloid receptor $1 \mathrm{ex}$ pressed on dendritic cells. Proc Natl Acad Sci USA 2005; 102:5120-5125.

27 Toth BI, Benko S, Szollosi AG, Kovacs L, Rajnavolgyi E, Biro T: Transient receptor potential vanilloid-1 signaling inhibits differentiation and activation of human dendritic cells. FEBS Lett 2009;583:1619-1624.

28 Caceres AI, Brackmann M, Elia MD, Bessac BF, del Camino D, D'Amours M, et al: A sensory neuronal ion channel essential for airway inflammation and hyperreactivity in asthma. Proc Natl Acad Sci USA 2009;106: 9099-9104.

-29 Conrad ML, Yildirim AO, Sonar SS, Kilic A, Sudowe S, Lunow M, et al: Comparison of adjuvant and adjuvant-free murine experimental asthma models. Clin Exp Allergy 2009;39:1246-1254.

>30 De Swert KO, Tournoy KG, Joos GF, Pauwels RA: The role of the tachykinin NK1 receptor in airway changes in a mouse model of allergic asthma. J Allergy Clin Immunol 2004; 113:1093-1099.

-31 Peebles RSJ, Hashimoto K, Sheller JR, Moore ML, Morrow JD, Ji S, et al: Allergen-induced airway hyperresponsiveness mediated by cyclooxygenase inhibition is not dependent on 5-lipoxygenase or IL-5, but is IL-13 dependent. J Immunol 2005;175:8253-8259.

>32 Le AV, Cho JY, Miller M, McElwain S, Golgotiu K, Broide DH: Inhibition of allergeninduced airway remodeling in Smad 3-deficient mice. J Immunol 2007;178:7310-7316.

-33 Walter MJ, Morton JD, Kajiwara N, Agapov E, Holtzman MJ: Viral induction of a chronic asthma phenotype and genetic segregation from the acute response. J Clin Invest 2002; 110:165-175. 